\title{
Neoliberalismo controlado: formação e desenvolvimento do sistema bancário-financeiro chinês
}

\author{
Pedro Henrique Neves de Carvalho*
}

Artigo recebido: 15 de fevereiro de 2019

Artigo aprovado: 30 de julho de 2019

Doi: https://doi.org/10.12804/revistas.urosario.edu.co/desafios/a.7707

Para citar este artigo: Neves de Carvalho, P. H. (2019). Neoliberalismo controlado: formação e desenvolvimento do sistema bancário-financeiro chinês. Desafíos, 32(1), 1-34. https://doi. org/10.12804/revistas.urosario.edu.co/desafios/a.7707

\section{Resumo}

O sistema bancário-financeiro chinês está no centro das transformacões sociais e produtivas da grande potência econômica asiática. Um sistema bá pouco organizado que alcança condições cruciais para a renovação da agenda econômica chinesa. Diante deste ponto, o artigo pretende reunir a agenda de transformação dessa estrutura a partir de uma leitura mais segura sobre a formação do shadow banking system chinês. Uma estrutura de crédito comum nos espaços financeiros neoliberais. Logo, organiza-se a pesquisa, metodologicamente, por meio de uma abordagem macro-bistórica, a observar os fatores de transformação estrutural da economia chinesa quanto à regulação bancária e financeira. E argumenta-se que esse processo expõe uma atualização sobre a prática neoliberal. Portanto, expõe-se uma interpretação acerca de um neoliberalismo controlado dadas as condicões de gerenciamento a partir das instituições públicas que formam o Estado Chinês. Como resultado desta pesquisa, apresenta-se as alteraçoes estruturais do neoliberalismo controlado da China a partir

\footnotetext{
* Centro Universitário de Belo Horizonte (UniBH). Correio eletrônico: neveshpedro@ gmail.com. ORCID: http://orcid.org/0000-0003-3023-1048
} 


\title{
2 I Pedro Henrique Neves De Carvalho
}

de: 1) o sistema bancário, 2) China development bank enquanto instituição primária para a renovação do crédito, e 3) a securitização dos passivos bancários por meio de investimentos em infraestrutura.

Palavras-chave: sistema bancário-financeiro chinês, shadow banking system, neoliberalismo, China development bank.

\section{Neoliberalismo controlado: formación y desarrollo del sistema bancario-financiero chino}

\begin{abstract}
Resumen
El sistema bancario-financiero chino está en el centro de las transformaciones sociales y productivas del gran poder económico asiático. Un sistema recientemente organizado que alcanza condiciones cruciales para la renovación de la agenda económica china. El artículo pretende reunir la agenda de transformación de esta estructura a partir de una lectura más segura sobre la formación del shadow banking system de China. Una estructura crediticia común en los espacios financieros neoliberales. Por lo tanto, la investigación se organiza metodológicamente a través de un enfoque macrobistórico, para observar los factores de transformación estructural de la economía china con respecto a la regulación bancaria y financiera. Y se argumenta que este proceso chino expone una actualización sobre la práctica neoliberal. Asi expone una interpretación acerca de un neoliberalismo controlado dadas las condiciones de gestión de las instituciones públicas que conforman el Estado chino. Como resultado de esta investigación, se presentan los cambios estructurales del neoliberalismo controlado de China desde: 1) el sistema bancario, 2) el banco de desarrollo de China como institución principal para la renovación de crédito y 3) la titulización de pasivos bancarios por inversiones en infraestructura.
\end{abstract}

Palabras clave: sistema bancario-financiero chino, shadow banking system, neoliberalismo, banco de desarrollo de China. 


\title{
Controlled Neoliberalism: Formation and Development of the Chinese Banking-Financial System
}

\begin{abstract}
The Chinese banking-financial system is at the center of the social and productive transformations of the great Asian economic power. A recently organized system that reaches crucial conditions for the renewal of the Chinese economic agenda. The article aims to gather the transformation agenda of this structure from a safer reading about the formation of the China's shadow banking system. A common credit structure in neoliberal financial spaces. Therefore, the research is organized methodologically through a macrohistorical approach, to observe the structural transformation factors of the Chinese economy with respect to banking and financial regulation. And it is argued that this Chinese process exposes an update on neoliberal practice. This exposes an interpretation about controlled neoliberalism given the conditions of management of the public institutions that forms the Chinese State. As a result of this research, we present the structural changes of China's controlled neoliberalism from: 1) The banking system, 2) The development bank of China as the main institution for credit renewal, and 3) Securitization of bank liabilities for investments in infrastructure.
\end{abstract} Keywords: Chinese banking-financial system, shadow banking system, neoliberalism, development bank of China.

\section{Introdução}

A Ásia, na contemporaneidade, se transformou em um espaço de maior importância para o capitalismo no sistema internacional. Uma importância que se atrelou ao dinamismo da economia japonesa em um passado recente e ao papel dos tigres asiáticos para os investimentos ocidentais. Mas desde o final da década de 1970 tem-se materializado por meio das transformações sociais-produtivas na China.

Acerca da China, com as atenções voltadas para o espaço social produtivo da mainland, há quatro décadas o governo operou uma ordem de transformações econômicas por meio da parte executiva do conselho de estado. Essas transformações deram espaço para uma construção 
sui generis em sua alçada financeiro-produtiva, a qual tem sido aperfeiçoada desde os primeiros anos da década de 1990 e, em função das suas evoluções práticas, passou a gerar desdobramentos em regiões, antes pouco próximas à China no trânsito financeiro/bancário, como a África e a América do Sul.

A relação financeira da China com outras regiões se expandiu quatro anos após a aproximação à OMC, o que hoje nos permite enxergar um processo programado de internacionalização da estrutura bancário-financeira do Estado que, apesar de recente, tem gerado grandes efeitos dentro e fora da China. ${ }^{1}$ É um capital que hoje tem vagado por outros continentes com diversas roupagens, como: o investimento externo direto das empresas chinesas que logram plantas produtivas, como as automobilísticas e as empresas de telefonia/comunicação; os empréstimos para o investimento em infraestrutura, que se garantem por meio dos recursos naturais da região; as recentes swaps de câmbio que internacionalizam o RMB por meio de uma cooperação entre bancos centrais.

A partir dessas observações, objetiva-se expor a organização do sistema bancário-financeiro da China, a partir da sua recente criação e do seu desenvolvimento. E esse exercício de retomada do processo de transformação bancário-financeiro permitirá expor a natureza das atualizações comerciais que sustentaram a internacionalização em soma ao projeto going out ${ }^{2}$ chinês. Projeto que foi apresentado pelo governo na aurora dos acordos da OMC e que permanece na atualidade. Seguindo

\footnotetext{
1 Acerca da mainland financeira há a relação com Hong-Kong, um passo importante para o fortalecimento das relações bancárias da China com o mundo, como também observa Green (2004) e Sung (2005).

2 Um processo observado como uma internacionalização das instituições financeiro-bancárias e das companhias estatais. Um processo, logo, também observado pelo quadro diretivo de alguns bancos, соmo ССB - http://www.ccb.com/en/newinvestor/ biogofdirectors.html; e ICBC - http://www.icbc-ltd.com/ICBCLtd/Corporate\%20Governance/Board $\% 20$ of $\% 20$ Directors/Board $\% 20$ of $\% 20$ Directors/, assim como a Comissão Nacional de Desenvolvimento e Reforma (CNDR) - https://www.uschina.org/policy/ national-development-and-reform-commission\#targetText $=$ The $\% 20$ National $\% 20$ Development $\% 20$ and $\% 20$ Reform,and $\% 20$ coordinating $\% 20$ major $\% 20$ economic $\% 20$ operations.\&targetText $=\mathrm{It} \% 20$ regulates $\% 20$ investment $\% 20$ projects $\% 20$ of $\% 20$ fixed $\% 20$ assets $\% 20$ in
} 
este propósito, o estudo sustenta a argumentação sobre uma prática financeira neoliberal controlada, por apontar em paralelo o desenvolvimento do sistema bancário-financeiro da China com as práticas das finanças internacionais consolidadas pelas forças econômico-políticas neoliberais no ocidente. Esse argumento é uma bússola para um primeiro exercício de compreensão sobre as finanças na China a partir da compreensão de um trato neoliberal.

O neoliberalismo e a economia chinesa são objetos que causam estranhamento. Logo, não se presume uma afirmação sobre uma condição neoliberal chinesa tal como uma ordem neoliberal britânica, estadunidense ou francesa. Mas almeja-se avaliar a proximidade entre as condições da prática financeira neoliberal e a organização do capitalismo chinês por meio da sua estrutura bancária. Por certo, o termo neoliberalismo trabalhado por este artigo caminha de encontro às discussões de Harvey $(2011,2006)$. A despeito deste fenômeno não representar uma condição homogênea no tempo e no espaço, seguir as orientações de Harvey implica em apontar para a constituição de uma agenda política, ou melhor, um projeto político enraizado nas transformações político-econômicas da década de 1970 que ampliaram as condições para a circulação do crédito, assim como determinou os meios para um processo de acumulação orientado pelo endividamento. Harvey afirma que o neoliberalismo surge como uma resposta às instabilidades vividas na década de 1960-1970 e que, conforme sugere Taylor (2010), corresponde a um programa de transformação institucional que leva as relações de mercado como condição imperativa para a organização da sociedade. Contudo, se soma à consideração de Harvey o que aponta Brown (2015) sobre o neoliberalismo. A despeito da sua observação ser debruçada sobre as democracias ocidentais, a autora informa que há um processo que converte as razões políticas constitutivas das ações democráticas em uma razão econômica a orientar, ou melhor, a minar os espaços democráticos. Essa complementariedade apresentada por Brown segue um argumento mais amplo, o qual resume à economicização

\%20China. e do Ministério do Comércio da República Popular da China (MOFCOM). http:/ / english.mofcom.gov.cn/ 


\section{I Pedro Henrique Neves De Carvalho}

das escolhas, dos costumes, das tradições, da política como ponto fulcral da orientação neoliberal. E a despeito dessa razão neoliberal ser a condição ontológica de orientação das escolhas na contemporaneidade, há indícios de uma era de transformações orientadas pelas instabilidades criadas pela conexão neoliberal atualmente. Em resumo, a condição material-histórica de Harvey e as colocações sociológicas de Brown constituem observações sobre um mesmo fenômeno e discutem a necessidade em orientar as escolhas políticas a partir de um ponto de vista econômico e financeiro. Enquanto Harvey afirma que o sincronismo geográfico neoliberal assiste às necessidades imanentes para a ampliação do capital financeiro, Brown observa como essa condição material histórica passa a ressignificar os diversos níveis institucionais de uma sociedade.

Agora, um entendimento sobre o shadow bank system chinês segue a observação sobre as transformações neoliberais que sustentam esse artigo. E em termos práticos, essa discussão passa pela relação entre China Development Bank (CDB), os investimentos em infraestrutura e os créditos podres do sistema bancário chinês. Essa tríade pode apontar para uma aparente contraditória aproximação entre o neoliberalismo e as finanças na China. Para tanto, observa-se um neoliberalismo controlado a partir do desenvolvimento bancário-financeiro chinês concernente à evolução do shadow banking system como uma variável dependente do modo social-produtivo neoliberal no ocidente, e a observação dos principais órgãos financeiros internacionais sobre este sistema; em segundo lugar se explorará a evolução do sistema bancário-financeiro chinês; e, por fim, explora-se o papel do CDB como uma variável dependente das inovações financeiras para a gestão dos créditos podres, ou créditos perdidos, em um processo de reciclagem financeira que permite observar uma parte de um neoliberalismo controlado dentro do capitalismo chinês.

\section{Shadow banking system}

Shadow Banking System (SBS) é um termo novo e há pouco reconhecido pelas organizações financeiras internacionais. É pouco monitorado e observado por instituições reguladoras, por grupos organizados na 
sociedade civil e por instituições privadas. Mas dada a sua importância para os Estados, presume-se que a estes atores internacionais o SBS tem prestado um papel interessante para o seu fortalecimento.

As razões de interesse sobre o SBS ganham força após a crise financeira de 2008-2009. Um momento que se expõe a inexistência de controle sobre as práticas variadas na intermediação financeira. Apesar de ser pensado como uma categoria pejorativa para as finanças em razão dos riscos atribuídos às práticas vinculadas aos produtos desta categoria bancária, o SBS é um resultado direto das inovações financeiras desde a década de 1970, momento no qual as atividades financeiras neoliberais passaram a constituir uma rede global de investimentos. Ou mais, uma condição social-produtiva que passara a ser ensaiada e transnacionalizada por meio das nações ocidentais.

Um dos principais temas que norteia o SBS é o seu tamanho diante da economia real, afirmando que as principais economias têm contribuído para o desenvolvimento de uma ampla rede de expansão creditícia e de investimentos, que vem a superar a estrutura real da economia produtiva mundial. O primeiro documento do Financial Stability Board (FSB) sobre o tema, apresentou os seguintes dizeres: “The 'shadow banking system' can broadly be described as "credit intermediation involving entities and activities outside the regular banking system" (FSB, 2011, p. 1). Na mesma linha, o FMI define o SBS como "credit intermediation outside the conventional banking system, constitutes about one-fourth of total financial intermediation worldwide" (IMF, 2014, p. 65).

A partir da crise de 2009 o sBS ganhou espaço nos meios da mídia e da sociedade civil, dados os efeitos observados do frenesi financeiro nos Estados Unidos da América. O espaço midiático criou uma alcunha pejorativa para esse sistema bancário, determinando-o como a condição prismática da turbulência vivida naquele momento. Entretanto, tanto para o Estado estadunidense, quanto para o Estado chinês o SBS é uma ferramenta alternativa relevante para o crédito, pois gera uma condição de oferta atrelada a produtos financeiros em condições não encontradas no mercado bancário tradicional, o que permite a 


\section{I Pedro Henrique Neves De Carvalho}

oferta de condições de juros atrativas em condição inversa ao risco. Entretanto, a condição da oferta do SBS coloca o caso chinês com maior destaque em função do papel dos grandes bancos comerciais e da política de crédito que orienta a maior parte dos empréstimos para as empresas estatais chinesas (Liansheng, 2015; Luo, 2016).

Neste exercício de compreensão é preciso avançar para pensar como um espaço social-produtivo que desenha uma linha tênue entre o crédito e os valores a uma indução econômica sadia ao lado do caos creditício ampliado por mecanismos de securitização. Por certo o SBS é uma alternativa ao sistema bancário da superfície financeira vista e controlada. Conforme o relatório de monitoramento do FSB de 2014 sobre 26 economias mundiais (desenvolvidas e em desenvolvimento) o SBS alcançou o valor especulado de 35.9 trilhões de dólares, ao representar $59 \%$ do PIB absoluto das nações avaliadas (FSB, 2014). ${ }^{3}$ Por sua vez, o FMI apontou que o elevado crescimento do SBS em proporção sobre o PIB formara o principal sinal de expansão do risco sobre os investimentos no palco internacional. Entre 2002 e 2012, por exemplo, o SBS passou de $6 \%$ para $35 \%$ sobre o PIB global, enquanto os ativos bancários alcançaram 70\% do PIB global no mesmo período (IMF, 2014).

E o primeiro passo formal para o desenvolvimento desta prática remonta à década de 1970 quando os primeiros produtos de securitização foram apresentados aos fundos de gerenciamento bancário de hipotecas e aos fundos de investimento por administração previdenciária. E como explicado por Chesnais $(1995,2005)$ houve um rearranjo econômico em um novo modus operandi, o neoliberal. E em diálogo com Chesnais, Luo (2016) indica as principais etapas desta transformação: a tentativa do governo dos EUA em controlar as ações bancárias por meio de juros elevados. Representado pela política do dólar forte na economia política internacional, esse episódio incentivou a criação dos SBS. A transferência da responsabilidade social do crédito da ordem bancária para o mercado de capitais também

\footnotetext{
3 Para acesso ao relatório: http://www.fsb.org/wp-content/uploads/r_141030.pdf
} 
indica uma atualização no modo social produtivo para uma ordem neoliberal, por alternar a distribuição de poder conforme autonomia do mercado financeiro nos EUA e, posteriormente, em toda ordem ocidental. Forjou-se uma prática suplementar de crédito por meio de novos produtos de investimento como o 'cash management account' (CMA), concomitante ao momento que bancos e outras instituições financeiras criaram os Money Market Mutual Funds (MMMFs). ${ }^{4}$

Entre 1980 e 1990 as inovações financeiras ganharam um processo de transnacionalização. E os modelos de securitização de crédito passaram para novos formatos a partir dos Mortgage-Backed Securities (MBS) e as posteriores derivações com os riscos nas mãos do intermediário financeiro emitente, como por meio das Collateralized Mortgage Obligations (CMO). ${ }^{5}$ Assim, a securitização das dívidas privadas, a partir das hipotecas individuais e corporativas, se transforma na maior inovação financeira, até as novidades apresentadas pelas Asset-Backed Securities (ABS). Em síntese, o processo de securitização do crédito, ou o que o Luo (2016) e Liansheng (2015) chamam de corrente de securitização, é o alicerce para o desenvolvimento do SBS no ocidente com elevado índice de derivações e de intermediários para uma espécie de "coletivização" do risco. E, por fim, a partir dos anos 2000 houve

4 CMA são contas costumeiras em corretoras que combinam serviços bancários (cheques a cartões de crédito), títulos, empréstimos em um único extrato. E os MMMFs correspondem aos fundos mútuos, ou melhor, ao mercado de compra e venda de ações a partir da operação e administração de uma empresa de investimentos que faz arrecadar os recursos do investidor e aplica-o de forma diversificada buscando a diversificação do investimento.

5 Os MBS correspondem a valores mobiliários em que juros pagamentos são garantidos por consórcios de empréstimos hipotecários. Em outros termos, são as ações que são lastreadas nos juros correspondentes aos empréstimos contraídos no mercado imobiliário/ residencial, em sua maioria. Já o CMO é uma garantia de renda fixa que se sustenta por meio de títulos lastreados em hipotecas como garantia. Logo, a existência do pagamento da hipoteca oferta uma renda aos compradores/investidores dos títulos emitidos a partir da contração de uma dívida no mercado imobiliário/residencial, em sua maioria. Por fim, as ABS são títulos, em sua maioria, que são criadas por bancos, empresas de cartão de crédito ou outros fornecedores de crédito e frequentemente «aprimorados» por uma letra de crédito bancária ou por cobertura de seguro fornecida por uma instituição diferente do emissor. Basicamente, corresponde a uma ação vendida por uma instituição financeira que corresponde a uma dívida ainda não quitada por um mutuário. E estes, entre outros termos, poderão ser consultados em Downes e Goodman (2006). 
um boom na integração financeira guiada pela revolução no palco das tecnologias de informação. Os bancos começaram a criar uma novidade na cesta de produtos financeiros: os Special Investment Vehicles (SIVs). Palco de grande discussão, esses produtos são gerenciados pelas subsidiárias bancárias com ações fora do balanço de capital dos bancos, o que reforçara a quantidade de capital creditício dentro do SBS. E conforme o FSB, esta evolução assumiria um peso percentual de $120 \%$ sobre o PIB mundial, o que pontua a discussão acerca do vigor do modo social de produção neoliberal por meio da condução financeira na contemporaneidade (FSB, 2015a).

Seguindo o relatório de monitoramento do FSB, os principais fatores de risco do SBS são encontrados. O primeiro alerta para o maturity transformation, que indica o uso de investimentos de risco em curto prazo originados de ações por provisão de crédito em investimentos de longo prazo; o segundo alerta recai sobre liquidy transformation, que indica a necessidade das autoridades acompanharem a expansão creditícia, apesar da dificuldade de mensuração; o terceiro alerta para o credit risk transfer, que indica os mecanismos de securitização e garantias apresentados pelas instituições financeiras dentro do processo de intermediação na oferta dos produtos. E, por último, mas não menos importante, o risco sobre a leverage que indica a preocupação sobre o grau de alavancagem das entidades financeiras com ou sem intermediários (FSB, 2015a).

Ainda sobre os riscos, Buitelaar (2014) afirma que a China vive uma grande contradição em sua estrutura bancário-financeira com os elevados retornos em ações e em empréstimos que poderiam mitigar a existência de riscos sobre o mercado bancário-financeiro chinês. Mas os riscos permanecem sobre as emissões de ações atreladas aos investimentos de longa duração em infraestrutura para as províncias, diante do retorno em curto prazo em um complexo processo de securitização. E para o autor, os maiores riscos se somariam a partir da estrutura do SBS em diálogo com o mercado imobiliário, dado o boom hipotecário pós-crise de 2009 criado em razão da indução do consumo, e o papel das autoridades locais 'financiando' os projetos 
de infraestrutura com poucos critérios comerciais para os investimentos (FSB, 2015b).

Por certo, a criação de um enforcement com objetivo de reduzir a exposição pelos mecanismos de securitização do crédito poderia reduzir a constância das crises financeiras. Por outro lado, por meio do FSB, junto ao regime bancário da Basileia, há um quadro de apresentação acerca da eficiência bancária que induz o desenvolvimento das inovações financeiras que podem alimentar o palco do SBS. O que para a sociedade civil é um espaço de constantes instabilidades, para as instituições financeiras e para os Estados há um cenário de complementariedade creditícia que tem dinamizado as economias nacionais.

Em uma tentativa de síntese sobre a relação do SBS com um sistema bancário convencional, é preciso procurar pelas diversas formas de derivação que circulam entre cinco grupos de instituições financeiras identificadas pelo FSB (FSB, 2013; 2014). Essas instituições, de cunho não bancário, criam as ordens de crédito sem a presença de depósito de clientes. E este simples componente diferencia as operações bancárias das operações de cooperativas de crédito. A construção do crédito sem a ordem do ativo por poupança não expõe essas instituições à exigência do grau de equidade, que é um mecanismo globalmente consentido como meio para o controle da expansão creditícia conforme o passivo bancário (Basileia I e II). Como as outras instituições financeiras não entram neste mecanismo global de controle, a expansão creditícia conforme securitização ou administração de fundos de investimento não encontra um mecanismo de enforcement.

Ainda, as instituições financeiras não bancárias aceleram as atividades econômico-produtivas criando liquidez em espaços sociais produtivos com condições distintas. Em caráter ilustrativo, os intermediários financeiros mencionados se organizam conforme a figura 1 . 
Figura 1. Sistema Bancário/sBS

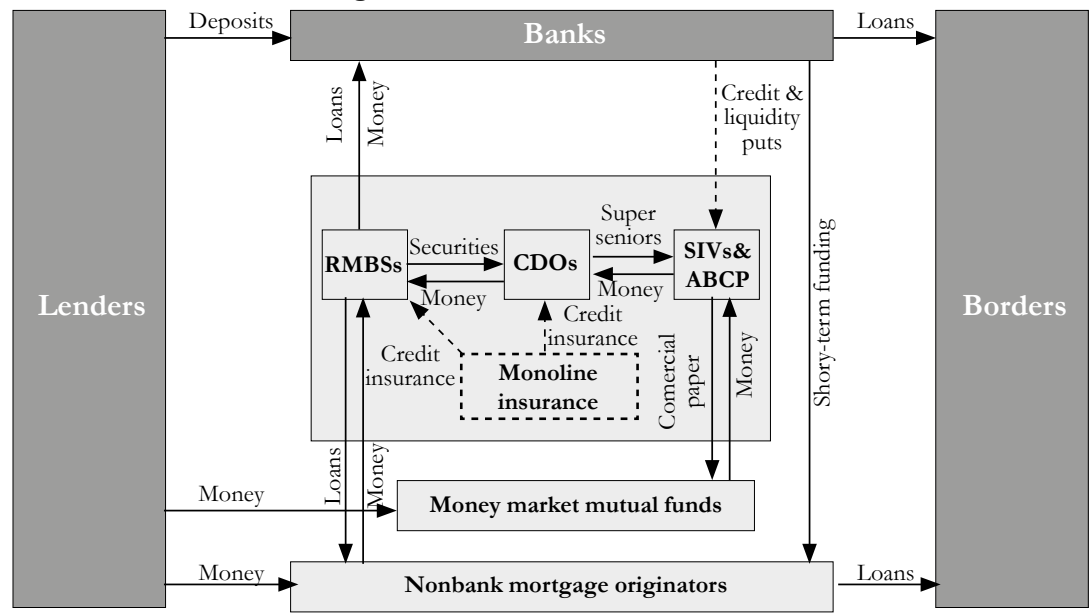

Fonte: IMF (2014).

Conforme o FMI, esta imagem (figura 1) representa a configuração dos fundos que migram do quadro dos credores para os mutuários. Esta imagem não tem uma representatividade universal porque a maior parte das intermediações é encontrada apenas nos mercados financeiros das economias mais avançadas. Por esse ângulo, a recente criação da estrutura bancário-financeira da China não se espelha nesse arranjo, mas, iguala-se nas derivações por securitização induzida pelos bancos titulares. ${ }^{6}$ A China não se iguala em um comparativo institucional, mas consegue criar uma ordem própria para exercer um controle governamental sobre a expansão do crédito que tem alimentado as suas transformações produtivas nas últimas décadas.

\section{As bases do moderno sistema bancário chinês}

A modernização do sistema bancário chinês se resume a dois fatores. O primeiro fator é a mudança de sistema econômico após 1978. Nesse momento a China migra de uma estrutura econômica socialista-Stalinista para um "socialismo de mercado", como defendido pelo conselho de

\footnotetext{
6 Asset-backed commercial paper (АВCP) conduits, collateralized debt obligations (CDOs), residential mortgage-backed securities (RMBSs), e structured investment vehicles (SIVs) (IMF, 2014).
} 
estado em 1993. Após 1978 há um modernização bancário-financeira, mas dada a sua diferenciação do modelo anterior não seria errôneo retratar o novo arranjo como uma ruptura sem precedentes na China contemporânea. O segundo fator é a abertura do sistema guiada por atualizações. A abertura do sistema bancário chinês pode ser compreendida em duas ações entre 1990 e 2006. Na década de 1990 houve o enquadramento dos bancos em dois grupos: os bancos comerciais e os bancos políticos. E no início dos anos 2000, pós acordos OMC, o governo abriu o setor de serviços, o que incluiu o palco bancário e financeiro para a participação estrangeira, conforme Li, Hsu e Qin (2013).

Entre 1978 e 1984 houve ainda, um momento de reformulação política, e entre 1984 e 1994 um segundo momento de reformulações, com o abandono do socialismo e um passo para o socialismo de mercado. $\mathrm{Na}$ esteira dessas atualizações, a partir de 1994 institui-se um novo sistema de controle macroeconômico, substituindo uma estrutura de centralidade e controle de planejamento pelo PBOC. Esse resumo, de acordo com Breslin (2007), esclarece algumas ações de descentralização como a eliminação da cota fiscal para a capitalização dos bancos comerciais e, após 2003, a criação da comissão reguladora, que é a organização responsável pelo processo de atualização bancária voltada para a governança corporativa ${ }^{7}$ (Naughton, 2010; Shambaugh, 2000, 2013).

A governança corporativa está no cerne das alterações do setor bancário e correspondem aos acordos da Basileia (BIS, 2003; 2011). Um termo norteador no palco financeiro internacional que direciona a caminhos e métodos trilhados para a eficiência bancária, como os termos encontrados nos princípios expostos pela OCDE na defesa do desempenho econômico (OECD, 2004). Com efeito, o sistema bancário serve ao estado/governo conforme os objetivos políticos estratégicos, e não o contrário. Mesmo com a mudança nas normas de propriedade, por permitir a participação pública, o governo é o sócio majoritário das instituições financeiras.

7 Para mais, conferir os White Papers: http://english.gov.cn/archive/whitepaper/ 
As mudanças na estrutura financeira da China partem da descentralização financeira diante de uma tradicional estrutura maoísta de centralização. A saída do estado planejador para um estado regulador não criou, na década de 1980, um modelo capitalista à revelia, mas permitiu a construção de algo novo a partir do desenvolvimento das Foreign Owned Enterprise (WFOE), do estabelecimento de regras para o investimento externo direto, e da formação de Joint Ventures. Nesse contexto é plausível pensar em um espaço social produtivo que vem a executar práticas financeiras neoliberais sem parear com a ordem neoliberal em equivalência à base anglo-saxônica. Um espaço social-produtivo que encuba, conforme Harvey $(2005,2006)$, o desenvolvimento intelectual, econômico e político neoliberal. Logo, no arranjo financeiro chinês há a possibilidade de um neoliberalismo financeiro controlado, algo possível a partir da redefinição do espaço social produtivo, ainda na década de 1990, para uma economia socialista de mercado orientada pelas razões da produção da riqueza conforme o crédito orientado pelo governo. Mas esta afirmação temporária precisa ser avaliada conforme um melhor entendimento acerca do singular sistema bancário chinês.

\section{A ordem bancária chinesa}

A primeira ação político-econômica da China que permitiu a reorganização do sistema produtivo partiu da pluralização do sistema bancário. Uma pluralidade que apaga da história o sistema monobancário da era maoísta. Um processo reconhecido como o passo mais sensível para a modernização do estado chinês que atrela as organizações burocráticas do governo às empresas estatais. É uma estrutura organizada para o financiamento dos projetos políticos por meio de um sistema especializado e capaz de criar condições favoráveis de crédito conforme o intento político dos governos regionais e de Pequim. Assim nasce um arranjo bancário-financeiro que tem potencializado o desenvolvimento da China e os seus desdobramentos em espaços econômicos pelo globo. 
A Comissão Reguladora Bancária Chinesa (CRBC) informa que o sistema bancário-financeiro chinês se resume a: 5 bancos estatais-comercias, 3 bancos políticos, 12 bancos de ações conjuntas voltados ao mercado de capitais (joint-stock commercial banks, JSCBs); 133 bancos comerciais municipais; um banco postal, 5 cooperativas rurais de crédito; 1.373 bancos comerciais rurais; 859 cooperativas bancárias rurais; 71 companhias financeiras e grupos corporativos; 224 trust companies; 68 financial leasing companies; entre outras, com uma soma oficial do estado de 4261 entidades. E para o gerenciamento dessa soma de organizações financeiras a CRBC e o BRPC amparam-se tanto para a observação sobre a governança corporativa, quanto para a solução dos créditos sem rendimentos (CBRC, 2015).

Contudo, entre 1948 e 1979 o Banco da República Popular da China (PBOC) era a única instituição bancária que, além de organizar a política monetária, também ofertava o crédito comercial para as atividades produtivas domésticas. Enquanto estrutura unitária se responsabilizava pelas práticas comerciais e pelas práticas político-econômicas esperadas de um banco central. Com o início das mudanças o BRPC manteve as ações voltadas para a administração da taxa de juros, do câmbio e da composição monetária. Apesar de ter abandonado o papel comercial com as mudanças estratégias após 1978, a antiga organização maoísta passou para o papel de supervisionamento das práticas bancárias entre a década de 1980 e 2000. Um papel que é, na atualidade, executado pela CRBC. Listando esses eventos soa uma irrelevância de datas que se somam como um fim figurativo. Mas o acompanhamento dessas atualizações com um olhar mais paciente permite expor um processo de aperfeiçoamento para que as práticas financeiras fossem adaptadas às condições internacionais sem reduzir a capacidade discricionária do Estado.

Em convergência, Luo (2016), Cousin (2011) e Okazaki (2007) relatam que esse processo de atualizações perpassa por algumas etapas. Primeiro, entre 1979-1985 funda-se o sistema bancário pluralizado, com o BRPC e o bloco dos big four a desenvolver a área comercial com 
setores restritos. ${ }^{8}$ Essa restrição dos quatro bancos estatais-comerciais representou um controle de crédito de banco por área. Não havia a autorização para migrar investimentos fora do seu espaço comercial (CBRC, 2016). ${ }^{9}$

O segundo movimento, entre 1985 e 1996, responde pela construção da legislação bancária e pela a criação/estabelecimento dos bancos políticos. ${ }^{10}$ E esses bancos nascem como gestores dos riscos em um espaço creditício inundado por empréstimos que se perderam em função da descentralização criada no início da década de 1980. Logo, esses bancos cumpriram o papel de gerenciar os empréstimos realizados pelos big four a partir dos setores da agricultura, da indústria, da infraestrutura e do câmbio/operações internacionais. E nesse ensejo, apenas em 1995 foram apresentadas a central bank law e a comercial bank law. ${ }^{11}$

A legislação bancária é o ponto de partida para compreender o diálogo mais tênue com o regime financeiro neoliberal a partir de 2001. E esse diálogo perpassa pelas aberturas públicas dos bancos estatais-comerciais para o investimento estrangeiro. Como afirmou Ma (1996), o progresso econômico chinês na década de 1990 esteve diretamente relacionado às inovações no sistema bancário-financeiro. Como a partir de 1983 os bancos passaram a assumir o papel de financiador das empresas estatais, houve uma estratégia de salvamento fiscal do governo, reduzindo o peso dos investimentos de uma fonte direta do orçamento do Estado. Essa reorganização para uma economia produtiva movida pelo crédito é relevante, pois uma estratégia inicial da receita virou um modelo de desenvolvimento específico. E este

\footnotetext{
8 Agricultural Bank of China (ABC), China Construction Bank (CCB), Industrial and Commercial Bank of China (ICBC) e Bank of China (BOC).

9 Conferir o organograma: http://www.cbrc.gov.cn/showindexlinks.do?s=dbi

10 Agricultural Development Bank of China (ADBC), China Development Bank (CDB) e Export-Import Bank of China (CEXIM).

11 Para a consulta das legislações: a) Comercial Banks - http://www.china.org.cn/english/ DAT/214824.htm b) Central Bank - http://www.npc.gov.cn/englishnpc/Law/2007-12/12/ content_1383712.htm
} 
modelo tem, desde então, combinado a evolução do sistema bancário/financeiro com os investimentos em infraestrutura, em produção e em tecnologia.

Segundo Luo (2016), é neste período que se nota o papel do BRPC como supervisor das ações bancárias e a "independência" dos demais bancos. E, por certo, essa descentralização se arregimenta a partir do ministério das finanças que deixa a condição de um órgão de controle e planejamento para se restringir a um órgão de supervisão. Ora, todas essas reformas organizacionais são importantes para explicar como se formou a indústria de crédito no sistema bancário chinês. E essas reformas permitiram a execução de um mecanismo de securitização de crédito seguindo um modus operandi neoliberal sob o intento do Estado para o seu fortalecimento.

O planejamento econômico, relegado das suas organizações antecedentes, passou para a responsabilidade do conselho de Estado da República Popular da China. Um conselho que se executa sob a direção do Primeiro Ministro (Li Peng, entre 1988 e 1998; Zhu Rongji, entre 1998 e 2003; Wen Jiabao, entre 2003 e 2013; e Li Keqiang de 2013 a atualidade). E seguindo as transformações do período 1985-1996, um quinto banco estatal-comercial foi criado: Bank of Communications (BOCOM). Por fim, os demais bancos menores, reduzidos aos governos locais ou municipalidades, passaram a ganhar espaço na cena

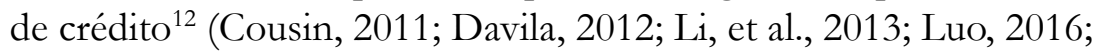
Sekine, 2010; CBRC, 2016).

A partir da terceira etapa almejou-se um novo ciclo no desenvolvimento do sistema bancário da China. Retomando, em síntese, as duas primeiras etapas alicerçam a ordem bancária para criar uma plataforma de crédito competitiva e voltada para alimentar a demanda criada a partir do crescimento econômico. Contudo, a terceira etapa importa para os ajustes de

12 Exemplo: Shenæhen Development Bank (SDB); China Merchants Bank (CMB) e Guangdong Development Bank (GDB). Ainda, os JSCBs: China CITIC Bank (CITIC), China Everbright Bank (CEB), Huaxia Bank (HXB), Shanghai Pudong Development Bank (PDB) e Fujian Industrial Bank (FIB). 
cenário. E estes ajustes serviram para fortalecer a condição creditícia e para reduzir a vulnerabilidade gerada pela descentralização econômica.

Essas ações corretivas no desenvolvimento bancário partem dos sinais negativos apresentados pelos empréstimos sem performance (Non Performing Loans, NPLs), a espiral inflacionária de 1994-1995 e a crise asiática em 1997. Frente ao excessivo número de NPLs criou-se as companhias para administração de ativos (Asset Management Companies, AMCs) com a responsabilidade de recuperar a qualidade dos empréstimos realizados por meio do processo de securitização via mercado de valores (Cousin, 2011; Li, et al., 2013; Wei, 2014). Essa estratégia abriu as portas para o início da prática de securitização dos investimentos dentro do circuito bancário chinês. E como pontuou Luo (2016), os empréstimos sem performance resultam dos seguintes fatores: o favorecimento de crédito para as empresas estatais em condições especiais criando uma demanda elevada em razão do reinvestimento produtivo dentro da China, e a descentralização econômica, dando autonomia a bancos, a empresas estatais e aos governos locais para alocar os investimentos e criar o crédito por demanda, sem critérios comerciais. E diante desses dois pontos, algumas variáveis contribuíram para minar a qualidade dos empréstimos realizados, como: a escalada da corrupção no sistema bancário, e a influência dos governos locais na construção de projetos e a indução de crédito dentro da rede, sem nenhum mecanismo de governança para a mensuração de resultado, e, o retorno para os bancos.

Em razão deste cenário o BRPC passou a controlar as taxas de juros, determinando o teto que os bancos poderiam pagar aos investidores do Estado, mas ao final da década de 1990 configurou-se o último ato mais substancial para a atualização do sistema: o abandono do sistema de quota de crédito, antes imposto pelo BRPC determinando o percentual de crédito para cada província. Essa decisão acelerou a competição bancária e o retorno dos bancos comerciais no final da década. Não menos importante, em 1996 a China formaliza a sua participação no regime da Basileia - Bank for International Settlements (BIS). Este movimento estratégico, segundo Okazaki (2007), serviu para favorecer a China diante das oportunidades do capital transnacional. Por certo, a entrada da China no 
palco da supervisão bancária internacional é construída a partir da concordância de Pequim com os Core Principles for Effective Banking Supervision (the core principles) (BIS, 2012).

A partir de 2001 cumpre-se outro passo importante do sistema bancário chinês com a abertura do sistema para a participação do capital estrangeiro. Essa é a observação que a maioria dos pesquisadores sobre o sistema bancário de China, como Cousin (2011), Luo (2016), Downs (2011), García-Herrero, Gavilá e Santabárbara (2006) characterized by massive government intervention, poor asset quality and low capitalization, has started a reform process based on the three main pillars: (i, Li, et al. (2013), Elliott, Kroeber e Qiao (2015), reportam interesse. Observam, como a China após 2001, passou a criar um espaço de oportunidade para os bancos privados ocidentais em semelhança à formação das joint-ventures da década de 1990, as quais foram desenvolvidas com o capital internacional-asiático e, posteriormente, com o capital internacional-ocidental.

O processo de internacionalização equivale à participação internacional do sistema bancário de China a partir de um dos seus braços políticos bancários: China development bank. Não há como separar a discussão presente acerca da internacionalização bancária da China determinando um único caminho de orientação. A internacionalização bancária chinesa é complexa e mescla o processo de entrada e saída de capital, o que reforça o interesse por ambos movimentos, não julgando a validade de um processo sobre o outro ou hierarquizando-os. A internacionalização do capital chinês é um resultado que se concretiza a partir do fortalecimento da economia da mainland. Contudo, a indústria do crédito e os bancos políticos, como o CDB, ocupam uma posição fulcral na indução desse processo de internacionalização que emerge com arroubo após as atualizações bancárias da década de 1990.

Os bancos foram transformados nos grandes indutores da economia chinesa, que ainda implica em um sistema de crédito que precisa ser fechado e/ou controlado por meio das peças principais reguladoras (BRPC e CBRC) para transformar os NPLs em novos ativos financeiros capazes de induzir o governo em novas rupturas produtivas. Daí a 
regulação bancária é necessária para manter a segurança não apenas das práticas financeiras, mas do controle do Estado via componentes essenciais atrelados ao conselho de Estado. A liberalização financeira permitiu introduzir novos veículos financeiros para construção da economia na China, mas esse argumento não pressupõe que o governo tem sido afastado da construção bancário-financeira com as reformas de mercado iniciadas com a descentralização do sistema.

A liberalização financeira na China passou pela introdução de práticas de mercado entre os bancos, sobretudo acerca da liberdade de investimentos e incentivo à competitividade que se somam às taxas de juros com influência do BRPC. O que se soma à abertura para participação do capital privado estrangeiro, assim como a autorização completa para a oferta de serviços bancários por instituições estrangeiras aos nacionais chineses (García-Herrero, et al., 2006)characterized by massive government intervention, poor asset quality and low capitalization, has started a reform process based on the three main pillars: (i.

A abertura ao capital estrangeiro, controlado sob o teto de $20 \%$ por organização bancária nacional, se sucedeu com a anuência dos Financial Stability Board, assim como a OCDE com avaliação da governança corporativa. Apesar de a organização reconhecer que não há um modelo para a governança corporativa eficiente, a construção de um palco gerencial composto pela participação dos shareholders, o peso do executivies boards e supervisiory board cumpririam o caminho para a eficiência de qualquer companhia bancária (OECD, 2004).

Em síntese, a partir dos dois principais órgãos de controle e monitoramento, o Banco da República Popular da China e a Comissão Reguladora Bancária da China, enraíza-se o Sistema Bancário Chinês. Os bancos comerciais, os Joint-Stock Commercial Banks, os bancos políticos e as demais instituições financeiras lideradas pelas trust companies formam o núcleo da estrutura do crédito bancário e não bancário na China. Por meio da combinação das organizações bancárias e não-bancárias se estabelece um fluxo de crédito de grande importância para a saúde econômico-financeira do sistema bancário chinês. As diferenças entre essas instituições serão posteriormente exploradas, 
e em resumo as demais instituições financeiras compõem o quadro mais sensível para o desenvolvimento do Shadow Bank System (SBS) chinês, o qual ganhou espaço a partir da combinação de duas variáveis político-econômicas chinesas: a) a necessidade de gerenciar os créditos podres - non performing loans (NPLS); b) a baixa oferta de crédito para as empresas médias e pequenas, guiando-as em uma busca creditícia secundária, ou fora da ordem bancária oficial do Estado.

\section{O shadow bank system chinês}

O sBS chinês é uma estrutura próxima ao SBS ocidental, mas é determinado por um processo de securitização de crédito de forma simplificada. Diante dessa simplicidade o BRPC depende do SBS como um elemento integrante do mercado financeiro que desempenha um papel proveitoso para facilitar os investimentos. Mesmo assim o BRPC tem ciência da "condição por vezes obscura e das falhas na supervisão do SBS, o que tende a apresentar implicações para as instabilidades financeiras" (PBOC, 2013, p. 199). A despeito da proximidade posta conforme o papel desempenhando pelo SBS, ambas as estruturas não se equivalem. A diferença pode ser observada a partir dos atores que permeiam o quadro da sociedade civil em cada um dos Estados Ampliados ${ }^{13}$. Enquanto no Ocidente atores privados ocupam o palco da descentralização, da securitização e da alavancagem, na China a mesma prática é simplificada com a posição dos Bancos públicos e com as trust companies determinadas pelo conselho permanente. Luo (2016) informa que o sistema financeiro chinês ainda permanece

13 Seguindo os argumentos de Coutinho (1999), há duas bases que dão forma ao Estado ampliado em Gramsci: a primeira parte da Sociedade política, que obtém "o monopólio legal da repressão e da violência". Se confunde com os aparelhos de coerção que estão no quadro das burocracias executiva e político-militar. A segunda é a Sociedade civil, que se forma com as organizações "responsáveis pela elaboração e/ou difusão das ideologias, compreendendo o sistema escolar, igrejas, partidos políticos, sindicatos, culturais, etc.”. Assim, aproximar essa discussão gramsciana sobre o problema deste paper implica em reconhecer que o SBS chinês se diferencia do SBS ocidental conforme os tipos de Estados ampliados que o alimenta. Enquanto no ocidente há uma descentralização para a formação do SBS, na China essa descentralização é controlada nos níveis do estado político, criando uma condição restrita do SBS para atender os interesses da classe política. 
dominado por um quadro formado por um pequeno número de grandes bancos. E a escala do SBS na China é menor em função dos atores envolvidos na intermediação financeira. Por isso defende-se que o mercado financeiro chinês tem um perfil simplificado. A despeito dessa característica, Buitelaar (2014) discute a dificuldade em se calcular o valor real do SBS, seja na China ou nas economias ocidentais. E a única alternativa conhecida é o agregado econômico social financining. ${ }^{14}$

Afora a discussão acerca do tamanho e da complexidade do SBS, o elemento basilar para a sua estruturação são os mecanismos de securitização a partir da derivação dos papéis das dívidas secundárias. Algo presente também na China por meio dos wealth management products (WMPs) que são ofertados no mercado pelos bancos comerciais — big four_ e pelas agências de crédito (Luo, 2016; Elliott, et al., 2015). ${ }^{15}$

A partir de 2004, com o lançamento dos WMPs, as trust companies ampliaram a oferta de crédito, reduzindo os meios tradicionais bancários por meio de depósitos/poupança. O que ganhou ainda mais força por meio do interbanking lending, com transações de elevado risco entre as instituições não bancárias que vendem as ações para os bancos como um processo de financiamento (Li, et al., 2013).

A despeito do aumento do crédito por meio das trust companies, os bancos permanecem como os agentes principais de indução do SBS em função dos endividamentos da economia chinesa. E com a presente capacidade de controle da comissão reguladora, os derivativos permanecem no nível de derivação das trust companies. Dado este cenário de controle sobre a derivação dos ativos atrelados ao mecanismo de securitização

\footnotetext{
14 Indicador que reúne o montante de financiamento da economia real que é fornecido pelo setor financeiro. Esse indicador é composto por: crédito bancário, títulos corporativos, patrimônio e atividades financeiras extrapatrimoniais dos bancos.

15 Wealth Management Products (WMPs) são as securitizações com prazos curtos de resgates (6 meses). Para a maioria dos produtos vendidos não é garantido o pagamento e pouco informada acerca da composição, o que implica em elevado risco. É quase-depósito bancário que migram entre os bancos. Para o FMI o mercado de WMPs comporia cerca de 14 trilhões de RMB na China, alcançando um valor maior que os ativos dos bancos (IMF, 2016).
} 
das dívidas dos bancos, a China encontrou um meio de controle financeiro a partir do desenvolvimento de seu sistema bancário-financeiro. Forja-se, assim, uma prática financeira neoliberal controlada.

Observa-se, pelas derivações e pela alavancagem no cerne da securitização, algo equivalente ao modus operandi financeiro neoliberal ocidental. Mas soma-se a essa ordem um mecanismo de controle que emerge das condições institucionais-políticas que caminham por um governo com capacidade única de gerenciamento. Entretanto, mesmo com esse arranjo, os NPLs permanecem, apontando para um problema crônico que acompanha todo sistema bancário-financeiro neoliberal.

E desde a instabilidade econômica chinesa de 1994 o processo de gerenciamento dos NPLs dialoga com os mecanismos de inovação financeira que alimentaram o SBS chinês (Li \& Zhou, 2016). É preciso cuidado para não apontar os NPLs como um resultado negativo da economia chinesa. Os empréstimos ampliados no processo de modernização bancária correspondiam às demandas apresentadas pelo rápido crescimento que vieram para sustentar a legitimidade da mudança. $\mathrm{E}$ como pontuado, a década de 1990 foi importante para sedimentar o modelo bancário descentralizado (HAO, 2006). O caminho construído perpassou pela criação de organismos gerenciadores das dívidas a partir do mercado de capitais. Por isso Breslin (2007) aponta que "enquanto os subsídios e os déficits orçamentários continuam a ser uma ferramenta-chave para melhorar os impactos perniciosos da reforma, o uso do sistema financeiro para conceder empréstimos às empresas favorecidas tornou-se cada vez mais importante" (p. 54).

A partir de 1994 a prática creditícia orientada conforme os interesses dos governos locais preencheram os meandros do sistema bancário com empréstimos não recuperáveis, alimentando a primeira grande crise financeira chinesa após a modernização do seu sistema.

Em síntese, desde a implosão dos créditos podres o governo tem conduzido a dois resultados por meio do mercado de capitais: o aumento da oferta do crédito doméstico por meio dos intermediários no mercado de capitais (trust companies); o gerenciamento da produção 
dos bad loans a partir das agências de gestão de ativos. Como já mencionado, essas agências são braços dos bancos comerciais e atuam como agências independentes com a responsabilidade de converter os NPLs em uma engrenagem de reciclagem de crédito (Cousin, 2011; García-Herrero, et al., 2006). ${ }^{16}$

O BRPC ainda manteve o seu papel de indutor fiscal e de agente de resgate nos momentos de maior instabilidade, como em 1998 com a injeção de mais de 270 bilhões de RMB e empréstimos direcionados aos bancos comerciais. Em 2003 uma nova onda de liquidez foi criada com o repasse de 45 bilhões de dólares destinados ao banco da China e ao banco da construção da China. E essas buscas por liquidez se potencializaram com a abertura pública (IPO) - initial public offering, dos bancos comerciais (Breslin, 2007; Mcguinness \& Keasey, 2010). ${ }^{17}$

Há um meio de controle no processo de desenvolvimento do sistema bancário-financeiro chinês. Algo que permite avaliar o socialismo de mercado como uma demarcação a fim de desenvolver um modo social de produção sem a subtração do poder do governo, sobretudo do conselho de Estado. E dadas as características do Estado ampliado chinês, o processo de inovação financeira, que se cria em função da descentralização bancária na construção de uma estrutura social produtiva neoliberal, não lesa o governo central, em razão dos mecanismos de controle das derivações e de recuperação por meio dos bancos públicos, conforme as ações de reciclagem de crédito operadas pelas AMCs. Por um lado, há uma ordem de securitização que dinamiza o crédito e a economia como um todo, a partir de um organismo econômico-político do Estado; por outro, como resul-

\footnotetext{
16 As principais $\mathrm{AMC}_{\mathrm{s}}$ chinesas: Huarong Asset Management Company (Huarong AMC), que representa o ICBC; a Orient Asset Management Company (Orient AMC), que representa o BOC; a Great Wall Asset Management Company (Great Wall AMC) que representa o ABC; a Cinda Asset Management Company (Cinda AMC) que representa o CCB e a Huida Asset Management Company (Huida AMC) (CBRC, 2015; PBOC, 2014, 2015).

17 Essas ofertas públicas iniciaram em 1991, mas ganharam mais espaço no mercado bancário a partir dos anos 2000, após o acordo com a OMC, seguindo os exemplos do China Merchant Bank (2002), Bank of China e ICBC (2006), entre outros (Mcguinness \& Keasey, 2010).
} 
tado das institucionalizações na soma acordos da Basileia e OMC, a Comissão Reguladora Bancária (2003) representa o mecanismo de survelliance sob a justificativa de uma estabilidade mínima de governança corporativa. E dentro das competências da comissão reguladora estão tanto o cumprimento das taxas de equidade ordenadas por meio de Basileia I e Basileia II, bem como a listagem das principais companhias estatais no recém integrado mercado de capitais Shangai/ Hong Kong (Bonin \& Huang, 2000; Li \& Zhou, 2016; PBOC, 2014). ${ }^{18}$

A despeito das análises indicarem as AMCs e as IOPs como os passos principais das inovações financeiras, o papel desempenhando pelo Chinese Development Bank (CDB) ganha destaque no amplo processo de securitização dos investimentos, somando-os ao projeto político-econômico do going out chinês. Este banco foi a pedra angular para a securitização e expansão do capital chinês.

\section{Policy banks: $O C D B$}

Decerto, como discutido, os NPLs são problemáticos, mas o seu gerenciamento oferece à China as condições para a expansão dos produtos de crédito e financeiros. Enquanto o primeiro boom dos NPLS resultou da descentralização bancária da década de 1980, o segundo momento resultara das inovações de crédito reciclados com novos investimentos em infraestrutura, tanto dentro quanto fora da China.

Pauta-se um paradoxo, mas a cada momento de instabilidade pelo aumento dos créditos sem retorno, alimenta-se a capacidade da China em ampliar os investimentos fora da mainland. O que se percebe no atual momento financeiro da China, particularmente com os investimentos em infraestrutura, é um resultado de uma recente transformação bancário-financeira que exige que os investimentos venham a se expandir em função do mecanismo de securitização dos passivos bancários. E parte significativa desses novos investimentos são reunidos debaixo de um termo significativo: o going out chinês. 18 Conferir a legislação: Share Issue by Public Companies and Rules on IPO and Listing on Stock.
Exchanges: http://english.sse.com.cn/laws/framework/c/3978488.pdf 
O going out chinês posiciona no centro desta estratégia político-econômica os bancos políticos, com maior destaque para o China Development Bank (CDB). Um banco com características transnacionais e com ênfase nos investimentos em infraestrutura. É neste contexto que o maior banco de desenvolvimento da atualidade ganha (Wang, 2015). E hoje o CDB é um banco de desenvolvimento com uma posição de destaque. Entretanto, somente a partir de 2001 que este banco passou a mesclar investimentos em outras regiões fora da China. A despeito do seu alcance no sul global, o CBD é um banco que estrutura o seu ativo a partir a emissão de issue bonds dentro do circuito financeiro do Estado, com uma prática de gerenciamento dos NPLs antes da criação das AMCs (CDB, 2011). Por isso é possível afirmar que o modelo das AMCs que hoje gerencia os créditos podres, é uma derivação do papel executado pelo CDB no início da década de 1990.

O banco se tornou a principal instituição financeira na alocação de recursos para investimentos de médio e longo prazo. ${ }^{19}$ Não obstante, o seu controle patrimonial está dentro da esfera do Estado e por isso é possível dizer que o banco cumpre além do papel atribuído a toda instituição financeira/bancária pela criação de crédito, o papel de agente de transformação econômico do governo. Logo, para além da intermediação creditícia o banco é uma ferramenta econômico-política. E sua composição patrimonial está atrelada ao ministério das finanças, à Central Hijin Investment Ltd e à Buttonwood Investment Holding Company Ltd (CDB, 2019).

A relação do $\mathrm{CDB}$ com os projetos em infraestrutura aponta para a solução dos desdobramentos negativos do crédito no setor bancário-financeiro. A partir desta interação se materializa um modelo que exige a expansão do crédito para a sobrevivência de toda ordem financeira, o que permite afirmar que os investimentos em infraestrutura fazem

\footnotetext{
19 A partir do relatório anual, CDB comporta ativos acima dos 12 trilhões de RMB. Este valor transita nos braços domésticos do banco, bem como por meio das subsidiárias como a CDB capital, CDB securities, CDB leasing, e pelos fundos como o China-Africa Development Fund (CAD Fund) e CDB Development Fund e o Sino-Latin American Production Capacity Cooperation Investment Fund (CDB, 2011).
} 
parte do processo de securitização por meio da reciclagem que o CDB começou a executar a partir da década de 1990.

A despeito do banco apresentar um perfil transnacional, o seu propósito de formação era gerenciar os créditos podres produzidos pelos governos locais, em função da expansão creditícia que resultou da descentralização do sistema bancário-financeiro da China. Assim, entre 1994 e 1998 o banco desempenhou um papel para a gestão dos NPLs, que hoje é executado pelas $\mathrm{AMC}_{\mathrm{S}}$ dos bancos estatais comerciais.

Há uma prática de recuperação de créditos podres a partir da securitização dos passivos dos bancos. Contudo, essa prática fora antes observada por Levine (1997) diante da expansão dos derivativos estadunidenses em razão do aumento do consumo por crédito. Esse aumento caminhou, em paralelo à multiplicação de bancos de investimentos, fundos mútuos e leasing companies nas praças financeiras anglo-saxãs. Um elevado número de instituições financeiras que ampliavam a securitização via mercado secundário, a despeito das discussões econômicas sobre o papel do investimento em infraestrutura como mecanismo de securitização. Além da secundarização excessiva observada nas praças financeiras anglo-saxãs, não houve uma aplicação desse modelo financeiro para a China. O espaço social-produtivo chinês conduziu a securitização dos créditos perdidos com a emissão de bônus dos títulos das dívidas guiados em novos investimentos em infraestrutura. E o principal momento para o início dessa agenda ocorreu na cidade de Wuhu, província de Anhui. O que atualmente é conhecimento como o Modelo Wuhu de desenvolvimento e securitização de crédito por meio do CDB (Sahoo, Dash \& Nataraj, 2011).

Em suma, observa-se na China uma integração financeiro-produtiva conformados pelos bancos (políticos e estatais comerciais), os produtos financeiros dos empréstimos junto à sua intermediação (os principais shareholders em $\mathrm{CDB}$ e os shareholders mais as trust companies com os big four), e as empresas estatais. Em conformidade com esta observação Downs (2011) aponta o banco como uma ponte entre os objetivos estratégicos do governo chinês e as atividades comerciais das empresas chinesas. 
Retoma-se a discussão do marco financeiro neoliberal a partir da gestão dos NPLs. E esses elementos financeiros são variáveis e dependentes da estrutura do sistema. Desde o momento de sua fundação, o CDB mantém o seu papel estratégico para reciclar os NPLs que constantemente se elevam em função da ampliação e dinamização da economia chinesa. (Huang, 2008; Sanderson \& Forsythe, 2013). Conforme Sanderson e Forsythe (2013), essa estratégia apoiou os investimentos em infraestrutura e fez da extensão dos empréstimos uma plataforma para securitizar o capital investido. À medida em que os NPLs foram reciclados e os novos projetos passaram a apresentar resultados comerciais, o banco começou a vivenciar um quadro de equidade antes não pensada.

O CDB passou a reavivar os passivos bancários na China em um circuito fechado de alavancagem, no qual a ordem capitalizada por meio dos bônus emitidos permanecia dentro do Estado (Wang, 2015). Esse modelo difere do modelo de securitização neoliberal operado nas praças financeiras anglo-saxãs. $\mathrm{Na}$ China se fundou um complexo financeiro que recicla, alimenta o setor econômico e propicia mais fatores de crédito para um crescimento econômico do Estado. Por isso é possível observar a importância deste banco para os governos locais, haja vista a construção do LGFV model - Local Government Financing Vehicles, criado para eliminar os NPLs pela combinação de valores, criando as condições para se recuperar parte dos créditos perdidos com a expansão de novos financiamentos (Buitelaar, 2014; Burlamaqui, 2015; Sanderson \& Forsythe, 2013; Wang, 2015). ${ }^{20}$

Diante do desenvolvimento deste processo de securitização, Tsui (2011) afirmou que a expansão de crédito chinesa de 2009 resultara do mesmo processo de alavancagem iniciado pelo modelo LGFV. Um novo processo de alavancagem, mas, seguindo as mesmas linhas de derivação/securitização. Este cenário de expansão creditícia com um mecanismo de controle de risco atrelado à terra criara a derivação do crédito por meio da emissão de bônus. Nesse cenário, a saúde da

\footnotetext{
20 Os LGFV são veículos financeiros locais que atrelam a condição do empréstimo para os governos locais com garantia por meio de terras/propriedades.
} 
produção desta liquidez exigiu a expansão creditícia a fim de renovar as emissões e combiná-las em empréstimos futuros, os quais ampliam a liquidez pela arrecadação apresentada com juros que acompanham as taxas comerciais, como bem expõe Gallagher (2016) e Ellis (2014).

No clímax desse arranjo o CDB, a partir das suas trust companies, como China Development Bank. Capital Co. Ltd. e a China Development Bank. Securities Co. Ltd passou a ampliar a escala dos investimentos a partir de 2005 com a sedimentação do going out por meio dos variados projetos em infraestrutura no sul global. Ainda, dada a criação de novos veículos e intermediários para a drenagem dos bônus a fim de evitar novas perdas por bad loans, o período após 2009 representou uma imagem semelhante ao boom de créditos podres do início da década de 1990 . O resultado direto, para então, uma nova etapa de securitização que sedimentou a atuação internacional do banco.

Nesses termos, no período após 2009, consolidou-se o terceiro ato de reorganização chinesa para controlar a queda dos títulos, em detrimento da ameaça de default sobre os investimentos pontuados. A internacionalização do $\mathrm{CDB}$ no início dos anos 2000 remonta a uma forma atualizada e moderna, a qual, em sua essência, mantém a representação original da financeirização neoliberal, mas sob os efeitos da condição matéria-histórica chinesa. E por essa condição revigora-se para que o crédito continue na linha de frente da formação do capital na China.

\section{Considerações finais}

O desenvolvimento do moderno sistema bancário-financeiro chinês representou um marco do amadurecimento do capitalismo na China. Desde o início do processo de descentralização do sistema bancário até as ofertas públicas de empresas da atualidade, o conselho de Estado tem organizado os mecanismos necessários para não perder o controle sobre o processo de securitização de ativos, o processo de alavancagem na relação crédito e bônus dos bancos comerciais. Apesar de recente, o modelo de crescimento econômico a partir 
da expansão do crédito nos permite compreender parte do pujante crescimento econômico chinês, assim como as partes que expõe suas fragilidades, para a continuidade deste crescimento.

Algo pertinente para discussões acerca da ordem financeiro-bancária chinesa se aplica a constante necessidade de investimentos, conforme as determinações dos investimentos em infraestrutura. Observado como um modelo doméstico para a recuperação dos empréstimos podres na década de 1990, ao longo do século XXI ganhou novas roupagens e tem, em parte, sustentado a internacionalização da China. Dadas as características destas transformações em diálogo com as características das práticas financeiras de derivações e securitizações em meio aos shadow banking systems, as características de survelliance e coordenação, têm permitido a China aprimorar uma prática que emerge da solidificação do modo social-produtivo capitalista em sua vertente neoliberal. Tal afirmação abre espaços para outras discussões, como a relação entre a propriedade e a criação de valor dentro do sistema econômico chinês. Mas como um primeiro passo para o entendimento de algo mais complexo, há um SBS controlado que aponta para uma transformação na prática financeira neoliberal.

Tal transformação não implica em uma hibridização, uma vez que apesar dos atores que mantém esse processo na China diferirem da condição orgânica das principais economias ocidentais, o princípio para a alavancagem e para a securitização permanece o mesmo. Ainda perdura a variável dependente para a circulação do capital por meio de novos investimentos, os quais recuperaram o valor dos ativos reciclados dos empréstimos anteriores apresentados no quadro econômico do Estado. O fim deste processo não é preciso, mas ao menos apresenta-se um horizonte para a compreensão das transformações que a China tem gerado em caráter transnacional.

\section{Referências}

Bank for International Settlements (BIS). (2003). Basel committee on banking supervision consultative document overview of the new basel capital accord bank. 
of international settlements publications. Basel. Recuperado de http://www. bis.org/publ/bcbsca03.pdf

Bank for International Settlements (BIS). (2011). Basel III: a global regulatory framework for more resilient banks and banking systems. Basel Committee on Banking Supervision Basel. Basel. Recuperado de http://www.bis. org/publ/bcbs189.pdf

Bank for International Settlements (BIS). (2012). Core principles for effective banking supervision. Basel. Recuperado de http://www.bis.org/publ/ bcbs230.pdf

Bonin, J. P., \& Huang, Y. (2000) Dealing with the bad loans of the Chinese banks. Discussion Paper Series 2. New York.

Brown, W. (2015). Undoing the demos: neoliberalism's stealth revolution. New York: Zone Books.

Buitelaar, P. (2014). Chinese banks - risks and challenges: occasional studies. Amsterdam: De Nederlandsche Bank NV.

Burlamaqui, L. (2015). Finance, development and the Chinese entrepreneurial state: a Schumpeter-Keynes-Minsky approach. Brazilian Journal of Political Economy, 35(141), 1-19.

Chesnais, F. (1995). Mundialização do capital. São Paulo: Xamã.

Chesnais, F. (2005). A finança mundializada: raízes sociais e politicas, configuração, consequências. São Paulo: Boitempo Editorial.

China Banking Regulatory Commission (CBRC). (2015). China Banking Regulatory Commission annual report. Beijing. Recuperado de http://www. cbrc.gov.cn/showannual.do

China Banking Regulatory Commission (CBRC). (2016). China Banking Regulatory Commission annual report. Beijing. Recuperado de http://www. cbrc.gov.cn/showannual.do

China Development Bank (CDB). (2011). Development finance in China: theory and implementatione. Singapore: Enrich Professional Publishing.

China Development Bank (CDB). (2019). Annual report. Recuperado de http://www.cdb.com.cn/English/gykh_512/ndbg_jx/2018_jx/

Cousin, V. (2011). Banking in China. New York: Palgrave Macmillan.

Davila, J. C. V. (2012). China's banking industry. Recuperado de http://centrum.pucp.edu.pe/pdf/working_paper_series/CEFE_WP2012-090019.pdf

Downes, J., \& Goodman, J. E. (2006). Dictionary of finance and investment terms. New York: Barron's. 


\section{I Pedro Henrique Neves De Carvalho}

Downs, E. (2011). Inside China, Inc.: China development bank's cross-border energy deals. Washington: Brookings Institution-The John L. Thornton China Center.

Elliott, D., Kroeber, A., \& Qiao, Y. (2015). Shadow banking in China: a primer economic studies at Brookings. New York. Recuperado de http://www. brookings.edu/ /media/research/files/papers/2015/04/01-shadow-banking-china-primer/shadow_banking_china_elliott_kroeber_yu.pdf

Ellis, E. (2014). China on the ground in Latin America: challenges for the chinese and impacts on the region. New York: Palgrave Macmillan.

Financial Stability Board (FSB). (2009). Report of the financial stability forum on enhancing market and institutional resilience. Recuperado de https:/ / www. bis.org/press/p080412.htm

Financial Stability Board (FSB). (2011). Strengthening the oversight and regulation of shadow banking. An integrated overview of policy recommendations. Recuperado de https://www.fsb.org/2012/11/r_121118/

Financial Stability Board (FSB). (2012). Global shadow banking monitoring report. Recuperado de http://scholar.google.com/scholar?hl=en\&btnG $=$ Search\&q=intitle:Global+Shadow + Banking + Monitoring+Report+2012\#0\%5Cnhttp://scholar.google.com/ scholar?hl=en\&btnG=Search\&q=intitle:Global+shadow+bankin$\mathrm{g}+$ monitoring + report $+2012 \% 230$

Financial Stability Board (FSB). (2013). Global shadow banking monitoring report. Recuperado de http://www.financialstabilityboard.org/wp-content/ uploads/r_131114.pdf?page_moved $=1$

Financial Stability Board (FSB). (2014). Global shadow banking monitoring report. Recuperado de http://www.financialstabilityboard.org/ publications/r_131114.htm

Financial Stability Board (FSB). (2015a). Global shadow banking monitoring report. Recuperado de https://www.fsb.org/wp-content/uploads/ global-shadow-banking-monitoring-report-2015.pdf

Financial Stability Board (FSB). (2015b). Peer review of China. Recuperado de http://www.fsb.org/wp-content/uploads/China-peer-review-report.pdf

Gallagher, K. P. (2016). The China triangle: Latin America's China boom and the fate of the Washington consensus. Oxford: Oxford University Press.

García-Herrero, A., Gavilá, S., \& Santabárbara, D. (2006). China’s banking reform: an assessment of its evolution and possible impact. CEsifo Economic Studies, 52(2), 304-363. 
Green, S. (2004). The development of China's stock market, 1984-2002: equity politics and market institutions. London: Routledge Curzon.

Hao, C. (2006). Development of financial intermediation and economic growth: the Chinese experience. China Economic Review, 17(4), 347-362. Harvey, D. (2005). A produção capitalista do espaço. São Paulo: Annablume.

Harvey, D. (2006). A brief history of neoliberalism. Oxford: Oxford University Press.

Harvey, D. (2011). O enigma do capital: e as crises do capitalismo. São Paulo: Boitempo Editorial.

Huang, Y. (2008). Capitalism with Chinese characteristics: entrepreneurship and the State. Cambridge: Cambridge University Press.

International Monetary Fund (IMF). (2014). Global financial stability report: risk taking, liquidity, and shadow banking curbing excess while promoting growth. Recuperado de http://www.imf.org/en/Publications/GFSR/ Issues /2016/12/31/Global-Financial-Stability-Report-October-2014-Risk-Taking-Liquidity-and-Shadow-Banking-41631

International Monetary Fund (IMF). (2016). The people's republic of China selected issues. Recuperado de https://www.imf.org/en/Publications/ CR/Issues/2016/12/31/The-People-s-Republic-of-China-Selected-Issues-44182

Levine, R. (1997). Financial development and economic growth: views and agenda. Journal of Economic Literature, 35(2), 688-726.

Li, G., \& Zhou, H. (2016). The systematic politicization of China's stock markets. Journal of Contemporary China, 564(feb), 1-16.

Li, J., Hsu, S., \& Qin, Y. (2013). Shadow banking in China: institutional risks. China Economic Review, 31, 119-129.

Liansheng, Z. (2015). The shadow banking system of China and international regulatory cooperation: new thinking and the new G20 series. Waterloo.

Luo, D. (2016). The development of the Chinese financial system and reform of Chinese commercial banks. Hampshire: Palgrave Macmillan.

Ma, J. (1996). China's banking sector: from administrative control to a regulatory framework. Journal of Contemporary China, 5(12), 155-169.

Mcguinness, P. B., \& Keasey, K. (2010). The listing of Chinese state-owned banks and their path to banking and ownership reform. The China Quarterly, 201 (may), 125-155.

Naughton, B. (2010). China's distinctive system: can it be a model for others? Journal of Contemporary China, 19(65), 437-460. 


\section{I Pedro Henrique Neves De Carvalho}

Organization for Economic Co-operation and Development (OECD). (2004). OECD principles of corporate governance corporate governance in Japan: from the viewpoints of management, accounting, and the market. Paris.

Sahoo, P., Dash, R. K., \& Nataraj, G. (2011). Infrastructure development and economic growth in China. Journal of Comparative Economics, 29, 95-117.

Sanderson, H., \& Forsythe, M. (2013). China's superbank: debt, oil and influence. How China development bank is rewriting the rules of finance. Singapore: John Wiley \& Sons.

Sekine, E. (2010). The international operations and future governance of China development bank. Chinese Capital Markets Research, 2(2), 1-17.

Shambaugh, D. (2000). The modern Chinese State. Cambridge: Cambridge University Press.

Shambaugh, D. (2013). China goes global: the partial power. Oxford: Oxford University Press.

Sung, Y. W. (2005). The emergence of greater China the economic integration of mainland China, Taiwan and Hong Kong. New York: Palgrave Macmillan.

Taylor, M. (2010). The contradictions and transformations of neoliberalism in Latin America: from structural adjustment to "empowering the poor". In L. Macdonald \& A. Ruckert, Post-neoliberalism in the Americas. EUA: Palgrave Macmillan.

The People's Bank of China (PBOC). (2013). China financial stability report. Recuperado de https://www.imf.org/external/pubs/ft/scr/2011/ cr11321.pdf

The People's Bank of China (PBOC). (2014). China financial stability report. Recuperado de http:/ /www.centerforfinancialstability.org/fsr/chn_ fsr_201407.pdf

The People's Bank of China (PBOC). (2015). Annual report. Recuperado de http://pic.bankofchina.com/bocappd/report/201604/ P020160427507129146288.pdf

Wang, Y. (2015). The sustainable infrastructure finance of China development bank: composition, experience and policy implications. Boston: Boston University Press.

Wei, J. (2014). The future of shadow banking in China. Columbia Business School Research Paper No 16-33. 